\title{
Characterization of isolated bacteria from burn patients and its susceptibility against different antibiotics in district Swat
}

\author{
Muhammad Nazir Uddin ${ }^{1}$, Braikhna Jabeen ${ }^{1}$, Qaisar khan ${ }^{1}$, Shah \\ Naeem $^{1}$, Wajid Khan ${ }^{1}$, Saadat Mehmood ${ }^{2,4}$, Muhammad ${ }^{1,2 *}$ and \\ Muhammad Rizwan ${ }^{3}$ \\ 1. Centre for Biotechnology and Microbiology, University of Swat, Khyber Pakhtunkhwa-Pakistan \\ 2. Department of Microbiology, University of Swabi, Khyber Pakhtunkhwa-Pakistan \\ 3. Department of Microbiology and Biotechnology, Abasyn University Peshawar, Khyber Pakhtunkhwa-Pakistan \\ 4. Center of Biotechnology and Microbiology, University of Peshawar, Khyber Pakhtunkhwa-Pakistan \\ *Corresponding author's email: muhammad@uoswabi.edu.pk \\ Citation \\ Muhammad Nazir Uddin, Braikhna Jabeen, Qaisar khan, Shah Naeem, Wajid Khan, Saadat Mehmood, Muhammad \\ and Muhammad Rizwan. Characterization of isolated bacteria from burn patients and its susceptibility against \\ different antibiotics in district Swat. Pure and Applied Biology. Vol. 7, Issue 1, pp121-132 \\ http://dx.doi.org/10.19045/bspab.2018.70015
}

Received: 23/10/2017 Revised: 22/12/2017 Accepted: $25 / 12 / 2017$ Online First: 10/01/2018

\section{Abstract}

Burn is an injury to the skin or other body tissues caused by various agents like thermal injury, scalds, fire, electrical shock and chemical injury. The aims of current study were isolation, identification and sensitivity of isolated bacteria against antibiotics from burn infected patients of District Swat. A total of 50 swab samples were collected from 50 burn infected patients. On the basis of colony morphology and Biochemical tests, including Oxidase, Catalase, Coagulase, Indole, and Motility eight different bacterial isolates were identified, including Bacillus, Enterobacter, Epidermis, E.Coli, Klebseilla, Pseudomonas Aeruginosa, Proteus and Staphylococcus aureus. The frequency range were Bacillus (0.3\%), Enterobacter 6.97\%), Epidermis (6.97\%), Proteus (9.30\%), E.coli (11.62\%), Klebsiella (13.95\%), Staphylococcus aureus (20.93\%) and Pseudomonas aeruginosa (30.23\%). The maximum infections, i.e. $38 \%$ were reported in children's age group 1-5 years. The infections reported in females were $65 \%$ while males $35 \%$. A total of 12 antibiotics were tested in which levofloxacin and ciprofloxacin were found more effective. Moderate against Amikacin, Chloramphenicol and Gentamycin. Whereas Imipenem, Amoxicillin, Ceftriaxone were found less effective. Attention and concentration is need to avoid the infection in burn patients at distract swat. A further detail and comprehensive study is needed to avoid or reduce these infections.

Keywords: Antibiotic sensitivity; Bacteria; Burn Patients; District Swat

\section{Introduction}

Burn is an injury to the skin or other body tissues caused by various agents like thermal injury, scalds, fire, electrical shock and chemical injury [1]. Skin is the thin layer of tissue form the natural outer covering of body of a person or animal. It contains certain specific component of the innate immune 
system, which help to protect the host from pathogens. The skin has an immunological and neurosensory function. It may have other function like Vitamin D metabolism [2]. According to literature the burn injuries are classified into three different categories. These categories are based on the depth of injuries. The first degree burn is surficial burn that affects the upper surface of skin. It appears as red spots of the skin and sensitive to touch for three to five days [3]. Second degree are subcutinic and has effect on the under layer of the skin and causes blisters. In such injury the function of sweat glands is affected and may feel pain for six to eight weeks. Systemic burn injury is classified as third degree. In this class the injury extends to all layers of the skin, e.g. epidermis, dermis and hypodermis. A sever burn have many effect on the body and can penetrate deep skin layers, which causing muscle or tissue damage that effect every system of the body. It has effect on human immune system. The function of immune system is to protect cells from invasion by microorganisms. The body has three important immune defense systems, all of which are disrupted with burn injury [4]. The response of immune system to burn injury is immediate, prolonged and or severe. The effect of burn in individuals is immune suppression, with increased susceptibility to fatal systemic burn wound or sepsis. The burn wound has a greater incidence of infections because in burn wound the skin barriers is destructed extensively and also alteration of the cellular and humoral immune responses. Burns can also cause emotional problems such as depression. Moreover age, drug use, gender, seasonal, smoking, socio-economic status and sun exposure are the high risk factors for burns [5].

Globally, Burn is serious public health problem and approximately 265,000 deaths occur each year from fire alone. However, death rate from other form of burn, i.e. scalds, electrical burn, etc. are not reported. The mortality rates due to burn are high in developing countries than developed countries. The possible reasons may be poverty, overcrowding, illiteracy, undoubtly limited treatment resources and inaccessibility to sophisticated skills makes the management of burns more challengeable. In developed countries with high gross national per capita spends more on health sector which reflected a better health status [6].

Initially the burn site is free from all types of microbial contamination. Infection usually starts after 48 hours [7]. Major microbes, e.g. fungi and Bactria colonized in wounds. These microbes usually present as normal flora, or occur from external environments and from hospital environment [8]. The use of topical antimicrobials may retard microbial growth or prevent further colonization. When colonized, these microbes start penetrating the viable tissues. This penetration depends on their invasive capacity, local wounds and degree of immune response of the patients [9]. Among the fungal pathogens Aspergillus niger, Penicillin and Candida albicans are the most common cause of infection [10]. In different centers large numbers of deaths (63$75 \%$ ) from burns occurs due to sepsis. This causes the indiscriminate use of broad spectrum antibiotics causing multidrug resistant virulent flora [11].

Different microorganisms associated with burn infection are bacteria and fungi [12]. The percentage of fungal infection with burn wounds is about 6-15\% among the fungal pathogens. Aspergillus niger, Candida albinos, and Zygomycetes are the most common causative agent of infection [3]. The fungal colonization may also depend on body parts of patients, like candida is rapidly colonized on skin and mucus membrane of nose, throat, and gastrointestinal tract [13]. Bacteria both gram positive and gram negative are the most common cause of burn 
wound infections. The gram negative bacteria colonized in wound in first few days. Common gram positive organisms are methicillin-resistant S. aureus (MRSA), Enterococcus, group a beta-hemolytic Streptococcus and Coagulase Negative Staphylococcus [9]. Staphylococcus aurous is a group of bacterial strains gram positive and as non-motile small round shaped cocci. Additionally, it can cause various skin and soft tissue infections [14]. Normally it is catalase positive. Enterococcus are gram positive Cocci [15]. They are facultative anaerobic organisms, non-motile, non-spore forming and catalase negative Streptococcus pyogenesare non-motile, catalase negative non-spore forming round bacteria, causing many skin infections to life threating systemic diseases [16]. Propioni bacteria are gram positive anaerobic rod shaped bacteria. They are non-motile, not filamentous, catalase positive and are secondary agents of infected wounds and abscesses in humans and other animals.

Gram negative bacteria are the most common and serious infectious source in burn patients. Among gram negative bacteria the important microbes are Pseudomonas aeruginosa, a rod shaped motile bacterium [17]. It produces water soluble pigments which diffuse through the medium, e.g. Pyocyanin, Pyoverdine and Pyorubin [18]. Klebsiella pneumonia is a non-motile, encapsulated, facultative anaerobic, lactose fermenting and rod shaped bacteria. It is catalase positive and oxidase negative. E.coli is rod shaped, facultative anaerobic, motile normal flora. It is Catalase positive and Oxidase negative [19]. Proteusis motile, rod shaped bacteria. It is catalase and Urease positive and Oxidase negative [13].

\section{Materials and methods}

\section{Study Area}

The current study was carried out in laboratory of Centre for Biotechnology and Microbiology at University of Swat with the collaboration of Research and Clinical laboratory, Kanju. The study time was from January to August 2017.

\section{Sample collection}

The 50 sterile swabs samples were collected from burn sites aseptically at Saidu teaching hospital, Matta hospital, Khwazakhela Hospital and Kanju Burn Care Centre. Samples were collected from different body parts (hands, leg, chest, and abdomen) of burn patients and properly labeled with patients Name, Age, and Gender. The samples were taken to laboratory of Centre for Biotechnology and Microbiology at University of Swat for further processing.

\section{Media preparation}

Different media's were used for the growth of isolated agents such as Nutrient agar, Blood agar, and MacConkey's agar. The media was autoclaved for 15 minutes at $121^{\circ} \mathrm{C}$. Then antifungal was added to inhibit fungal growth and poured in sterilized petri dishes under aseptic environment in laminar flow hood (LHF).

\section{Swab culture}

Swab samples were streaked on Nutrient agar media. After streaking plates were incubated for 48 hours on $37^{\circ} \mathrm{C}$.

\section{Sub culture and pure culture}

Different Morphological colonies were appeared on Nutrient agar plates. To obtain pure culture subcultures of separated colonies were again sub cultured for 48 hours at $37^{\circ} \mathrm{C}$. Identification of bacteria

All cultures were examined for the growth and colony morphology. Gram staining and biochemical tests, e.g. oxidase, catalase, coagulase, indole, and motility were used for identification

\section{Antibiotic sensitivity test Antibiotic disk preparation}

For inoculums preparation a sterile distilled water ampoules were used. The inoculum of pathogenic bacteria were adjusted to 0.5 McFarland standards. In bacterial suspension a sterile cotton swab were dipped. In order to 
get a uniform growth of isolates, the isolated samples were streaked on Mueller Hinton agar with cotton swab smoothly. After 15 minutes of inoculation the antibiotic discs of known concentration were placed on the media surface with the help of disc dispenser. The list of antibiotics used in present research work is given in table 1 . The plates were then incubated for 24 hours at $37^{\circ} \mathrm{C}$ in inverted position. The zones of inhibition were measured after 24 hours.

\section{Antibiotic susceptibility test Disc diffusion Method}

Antibiotic susceptibility test Disc diffusion technique [Kirby-Bauer method] was used to test antimicrobial sensitivity. Sterile swab was soaked in the test organism suspension and swab was streaked over the surface of Muller Hinton agar. The Petri-dish was allowed for 3-5 minutes to dry, by using sterile forceps the antimicrobial discs were placed evenly distributed on inoculated plate. The plates were incubated aerobically at $37^{\circ} \mathrm{C}$ for 24 hours. The zones of inhibition around each disc were measured in millimeters and the results were reported as sensitive, intermediate and or resistant.

\section{Antimicrobial sensitivity Assay}

The antibiotic sensitivity tests were performed for isolated bacteria, e.g. Staphylococcus aureus, Pseudomonas aeruginosa, E.coli, Klebsiella, Epidermidis, Enterococcus and Proteous. Large numbers of antibiotics were used.

\section{Results}

During current research work the patients were distributed on the basis of various categories given below.

\section{Gender wise distribution of burn patients}

The Gender wise distribution for all 50 Burn patients were made and found that $35 \%$ were male while the remaining $65 \%$ were found female (Figure 1).

\section{Age group wise distribution of Burn patient's}

During age wise distribution of patients it were found that patients having age group 15 years were $(34 \%)$ followed by $10-15$ years (18\%), 15-25 years (24\%) and 25-35 years (6\%) (Table 2).

Burning source wise distribution of bacterial infection

The isolated bacteria were distributed on the basis of different source of burns. The result indicates that six bacterial isolates, i.e. Pseudomonas, Staphylococcus Aureus, E.coli, Klebseilla, Proteus, Epidermiswere found in high number. The bacteria including Pseudomonas, Staphylococcus Aureus, E. coli, Klebsiella, Proteus, Epidermis were recorded in burns of direct heat. Pseudomonas, Klebsiella, Staphylococcus Aureus, Epidermis, E.coli. Isolated from burn caused by accident. The Pseudomonas, E.coli, Proteus, Enterobacter Epidermis were recorded in burn caused by petroleum.

\section{Susceptibility of isolates against various antibiotics}

During study the pseudomonas aeruginosa was associated with maximum number of patients, i.e. 26, followed by $S$. aureus, Klebsiella, Proteus, and E.coli 18, 12, 10 and 8 respectively while Enterococcus and epidermis both were associated with 6 patients (Table 3). The susceptibility of Pseudomonas aeruginosa against various antibiotics were determined and found $60 \%$ sensitive to levofloxacin (LEV) followed by TZP and AK 45\% and 35\% respectively, $10 \%$ was recorded against MP while no activity were shown against IPM and TGC each (Figure 2).

Figure 3 revealed that klebsiella were found more sensitive against CIP, 55\% and LEV 65\%. Against AK, TZP, CPO recorded moderate while against $\mathrm{E}$ no activities were recorded. The bacteria proteus susceptibility were determined against various antibiotics and found susceptible against TZP (60\%), 
LEV (70\%) and CIP (65\%). While against AK, CPO, SCF moderate, i.e. $45 \%, 35 \%$ and $40 \%$ respectively. Similarly CAZ, AMC showed no effect against proteus (Figure 4). In case of E.coli showed high resistance against Amoxicillin (AMC) 100\% (Figure 5). The Staphylococcus aurous showed high resistance against Amoxicillin (AMC) 97.1\% as compare to the other antibiotics (Figure 6). The bacteria Enterococcus showed 100\% resistance to Erythromycin while less resistant to Ciprofloxacin (CIP) and Levofloxacin (LEV) recorded as $10 \%$ (Figure 7).

\section{Discussion}

Burn infection is a serious public health problem of Swat, Khyber Pakhtunkhwa. Burn injuries have body disinfection, lifelong difficulty even cause death [20]. The burn infection explores the tissue for microorganisms of normal flora and contaminated environment. The virulence factor for infection including adhesion, nutrients and immune system of the patient. To prevent and treat burn infection numbers of antibiotics can be used to administrate directly as topical cream taken by orally or by injections [21].

The results of current study showed $80 \%$ infection in burn patients. These results are in agreement with the study conducted by Mooney et al; 2004, who investigated the microbial association with burn patients [20]. Manjula et al; in 2004 isolated a number of different bacterial isolates from post burn infections, including S. Aureus, Epidermis and klebsiella [22]. These results are concise with our study, in which we isolated eight different bacteria including pseudomonas aeruginosa, staphylococcus aureus, klebseilla, E.coli, epidermis, Enterobacter, proteus and bacillus.

Adeyemi et al; in 2006 recorded in his study that most common burn infections were due to association of pseudomonas auregenousa, klebseilla, staphylococcus aureus, E.coli and epidermis [23]. The current study is in agreement with previous researcher. It is also in line with research work conducted by Barret et al; in 2002 [7].

In present study the higher frequency were recorded for pseudomonas auregenousa $30.23 \%$ followed by staphylococcus aureus $20.93 \%$, klebseilla $13.95 \%$, E.coli $11.62 \%$ Proteus $9.30 \%$, Enterobacter $6.97 \%$ and epidermis $6.97 \%$ (Figure 8 ). These results are in line with the results of [23]. The reasons for this high frequency of Pseudomonas aeruginosa, Staphylococcus aureus and Klebsella may be that they are present abundantly in air, can survive in waste range of environmental conditions and showing resistance against a number of antibiotics.

The present research work is also in conformations with the reports of [24]. The lowest frequencies of our results were noted in Enterobacter and E.coli that was $6.97 \%$ each which is in agreement with [25]. It is well documented that children's of age group 1-15 years are in high risk of getting burn injuries [5].

The results of our study revealed that highest percentage of burn injuries in age group 1-5 years were recorded followed by age group $5-10$ years $18 \%$. These results are in line with the research work conducted by Chees brough and his colleagues [26]. The reasons for high percentage are unaware about consequences of fire and carelessness of parents. The report of QUECH supports our results Komolafeet al; 2003 stated that likewise burn infection higher percentage were reported in age group 1-15 years of children's [27]. Our results are agreed with the previous studies of Zetola and friends and Church et al; 2006 [3, 14]. The reasons for this high infection percentage may be that child's are more active in daily life exposed to outdoor contaminated environment and unprotected wounds parts. Similarly $65 \%$ infections were reported in females which are higher than male $35 \%$. 
According to this study hands are more prone to burn injuries, i.e. highest percent infection $16 \%$ were noted in hands, followed by legs $13 \%$ chest $9 \%$, abdomen $8 \%$, face $04 \%$, arm fit $2 \%$ and back $1 \%$ the reports of the QECH also shows the same percentage [28].

Antibiotics resistance is the ability of bacteria to resist against antibiotics to which they were once susceptible. Bacteria associated with burn patients have high level of resistance to many antibiotics as burn patients generally take broad spectrum of antibiotics. About ten antibiotics with different generation and mode of action were tested against important bacterial isolates Pseudomonas, Staphylococcus aureus and Klebseilla are more resistive to antibiotics. The current study is in agreement with previous researchers [14].

Table 1. List of antibiotics with chemical name and Generation

\begin{tabular}{|l|l|l|l|l|}
\hline Serial no & $\begin{array}{l}\text { Commercial } \\
\text { name Antibiotics }\end{array}$ & Chemical name & Generation & Concentration \\
\hline 1 & CM & Gentacycol & $2^{\mathrm{ND}}$ & $10 \mathrm{mcg}$ \\
\hline 2 & AML & Amoxicillin & $2^{\mathrm{ND}}$ & $30 \mu \mathrm{g}$ \\
\hline 3 & AMC & Amoxillin & $2^{\mathrm{ND}}$ & $30 \mu \mathrm{g}$ \\
\hline 4 & ZOX & Ceftizoximum & $3^{\mathrm{RD}}$ & $30 \mathrm{mcg}$ \\
\hline 5 & MEM & Meropenemtrihydrate & $3^{\mathrm{RD}}$ & $10 \mathrm{mcg}$ \\
\hline 6 & AK & Amikacin & $3^{\mathrm{rd}}$ & $30 \mathrm{mcg}$ \\
\hline 7 & CE & Cefixime & $3^{\mathrm{RD}}$ & $30 \mu \mathrm{g}$ \\
\hline 8 & E & Abomacetin & $3^{\mathrm{RD}}$ & $30 \mathrm{mcg}$ \\
\hline 9 & SCF & Cefoperazine & $3^{\mathrm{RD}}$ & $75 \mu \mathrm{g}$ \\
\hline 10 & KAZ & Fortaz & $3^{\mathrm{RD}}$ & $30 \mathrm{mcg}$ \\
\hline 11 & CPO & $\begin{array}{l}\text { Cefepime } \\
\text { hydrochloride }\end{array}$ & $4^{\text {th }}$ & $30 \mathrm{mcg}$ \\
\hline 12 & TZP & Piperacillin anhydrous & $4^{\mathrm{TH}}$ & $110 \mu \mathrm{g}$ \\
\hline 13 & LEV & Levofloxaccin & $3^{\mathrm{rd}}$ & $5 \mathrm{mcg}$ \\
\hline
\end{tabular}

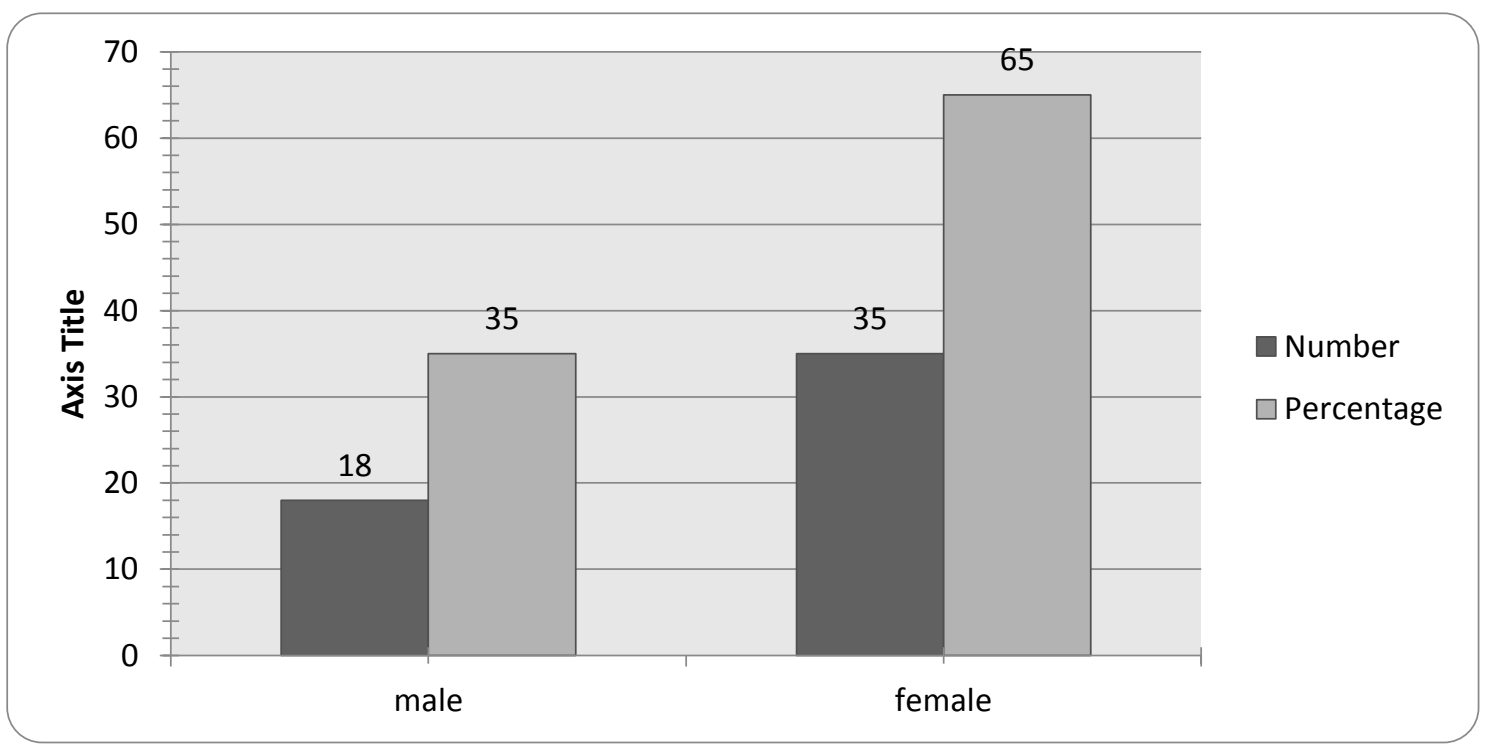

Figure 1. Gender wise distribution of burn infections 
Table 2. Age group wise distribution of Burn patient's

\begin{tabular}{|l|l|l|l|}
\hline S. No & Age & No of persons & Percentage \\
\hline 1 & $1-5$ & 17 & 34 \\
\hline II & $5-10$ & 10 & 18 \\
\hline II & $10-15$ & 07 & 14 \\
\hline IV & $15-20$ & 08 & 16 \\
\hline V & $20-25$ & 06 & 12 \\
\hline VI & $25-30$ & 02 & 4 \\
\hline VII & $30-35$ & 01 & 2 \\
\hline
\end{tabular}

Table 3. Source and types of bacteria in burn wounds

\begin{tabular}{|l|l|l|}
\hline S. No. & Source of burn & Bacteria name \\
\hline 1 & Direct heat & $\begin{array}{l}\text { Pseudomonas, Staphylococcus Aureus , E.coli, Klebsiella, } \\
\text { Proteus , Epidermis }\end{array}$ \\
\hline 2 & Fire & Pseudomonas, Staphylococcus aureus \\
\hline 3 & Hot water & Proteus, Pseudomonas , Klebsiella \\
\hline 4 & Hot Milk & Staphylococcus aureus , Epidermis , E.Coli , Klebsella \\
\hline 5 & Accident & $\begin{array}{l}\text { Pseudomonas, Klebsella , Staphylococcus Aureus, } \\
\text { Epidermis, E.Coli }\end{array}$ \\
\hline 6 & Cooking oil & Proteus , E.Coli \\
\hline 7 & Hot tea & Staphylococcus aureus , E.coli \\
\hline 8 & Electricity & Pseudomonas, E.coli, Klebsella \\
\hline 9 & Petrol & Pseudomonas, E.coli, Proteus , Enterobacter Epidermis \\
\hline
\end{tabular}

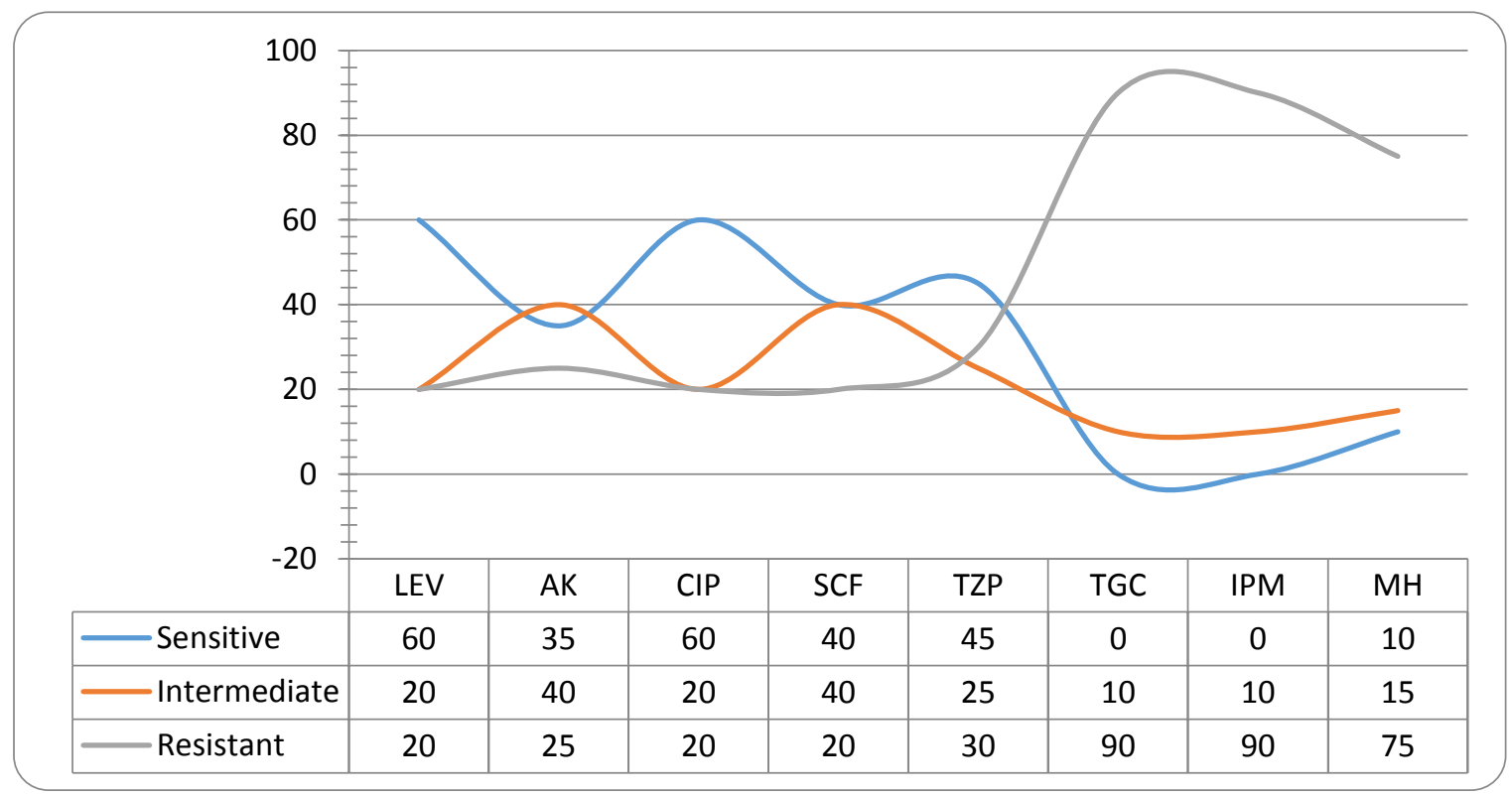

Figure 2. Susceptibility of Pseudomonas aeruginosa against antibiotics 


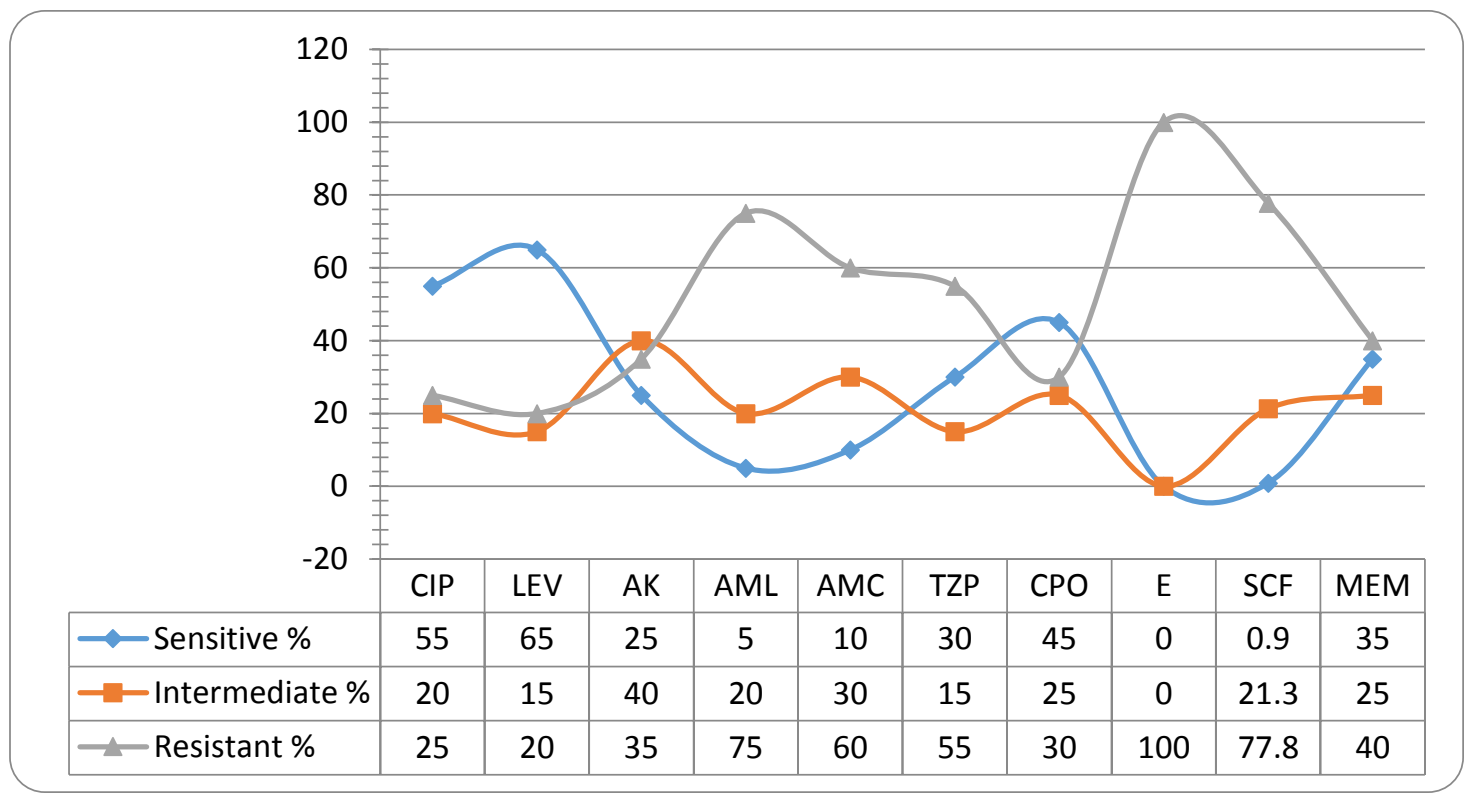

Figure 3. Antibiotic sensitivity tests against Klebsiella

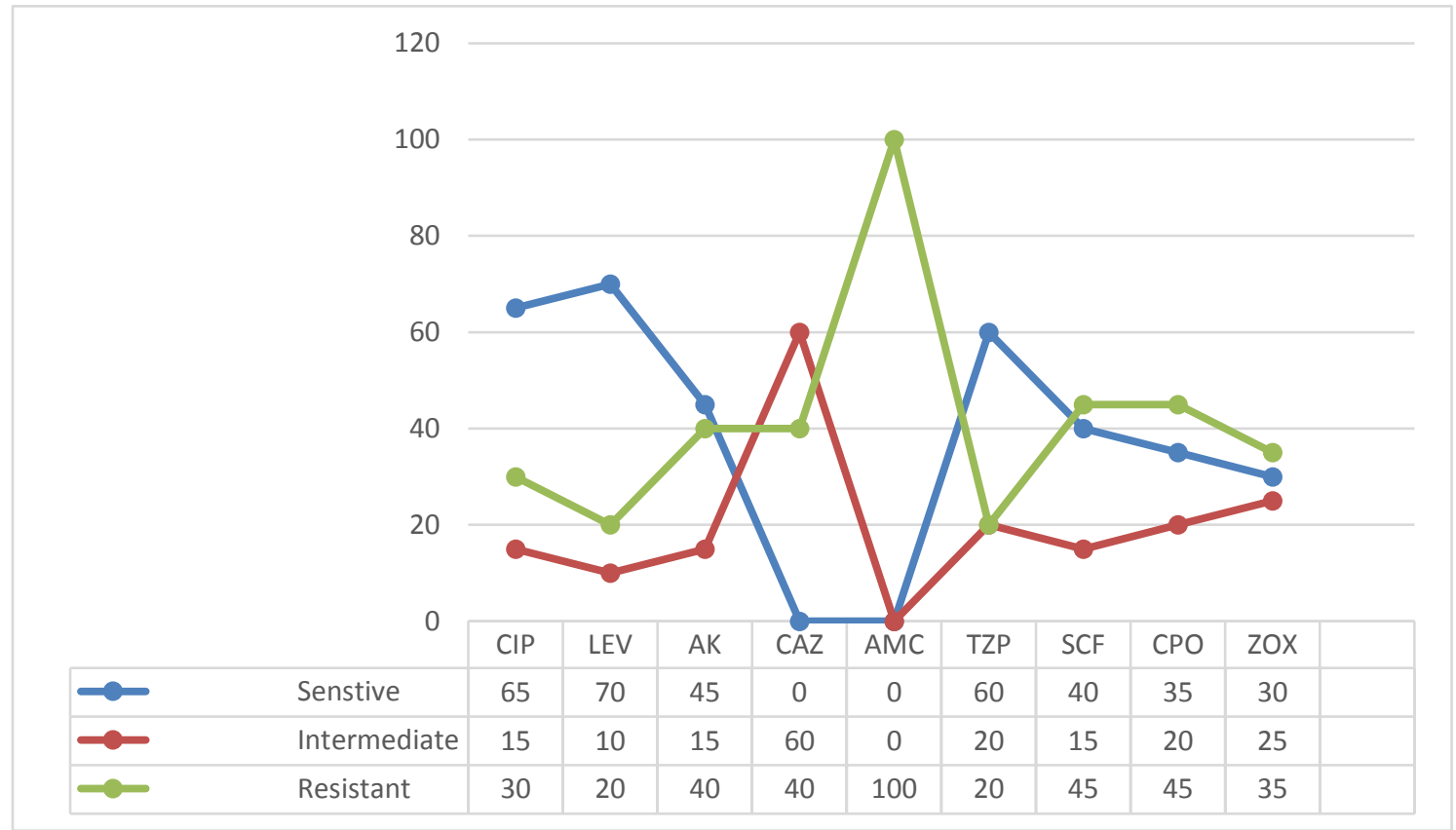

Figure 4. Antibiotics sensitivity test against Proteus 


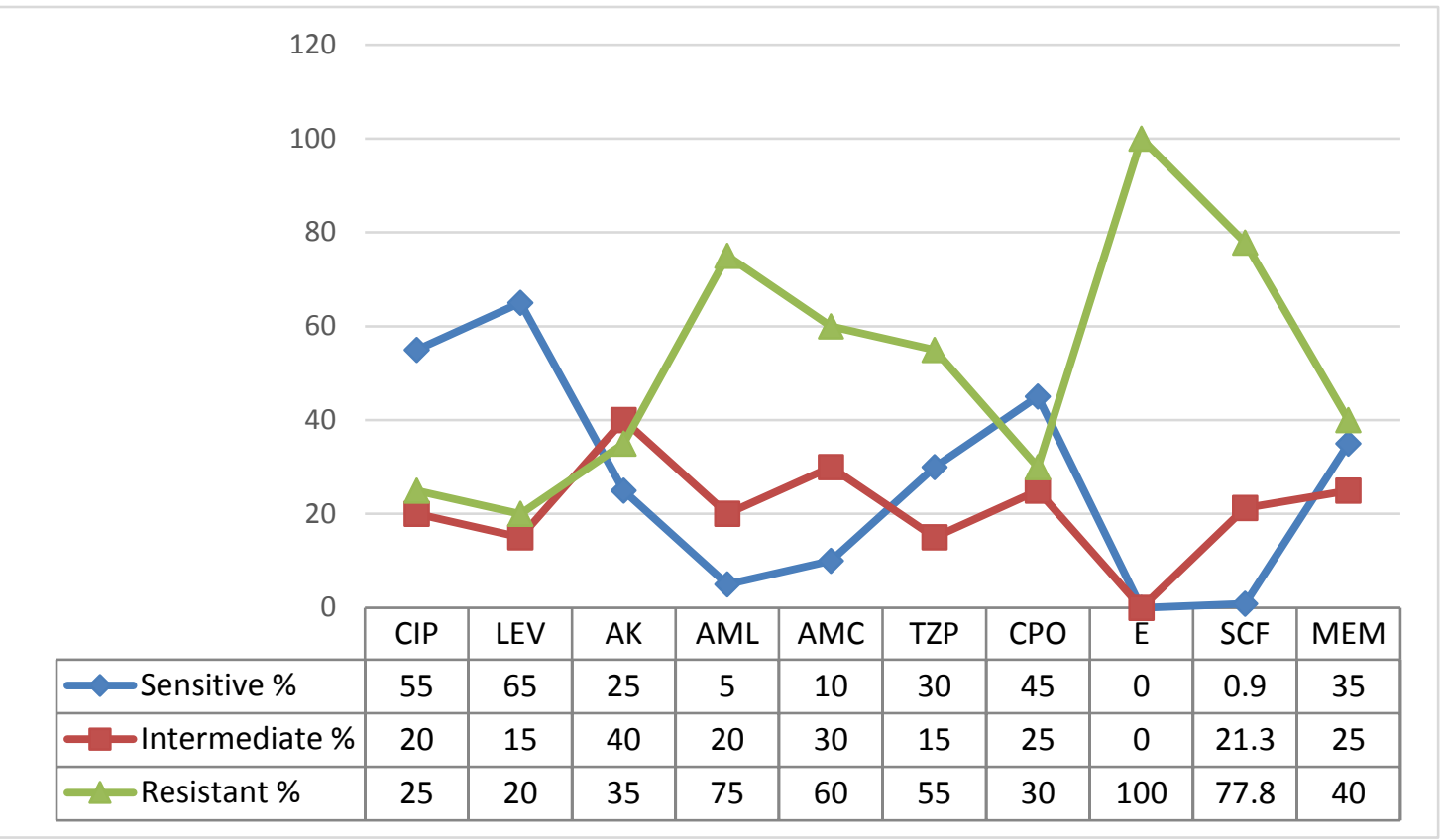

Figure 5. Antibiotic sensitivity tests against E.coli

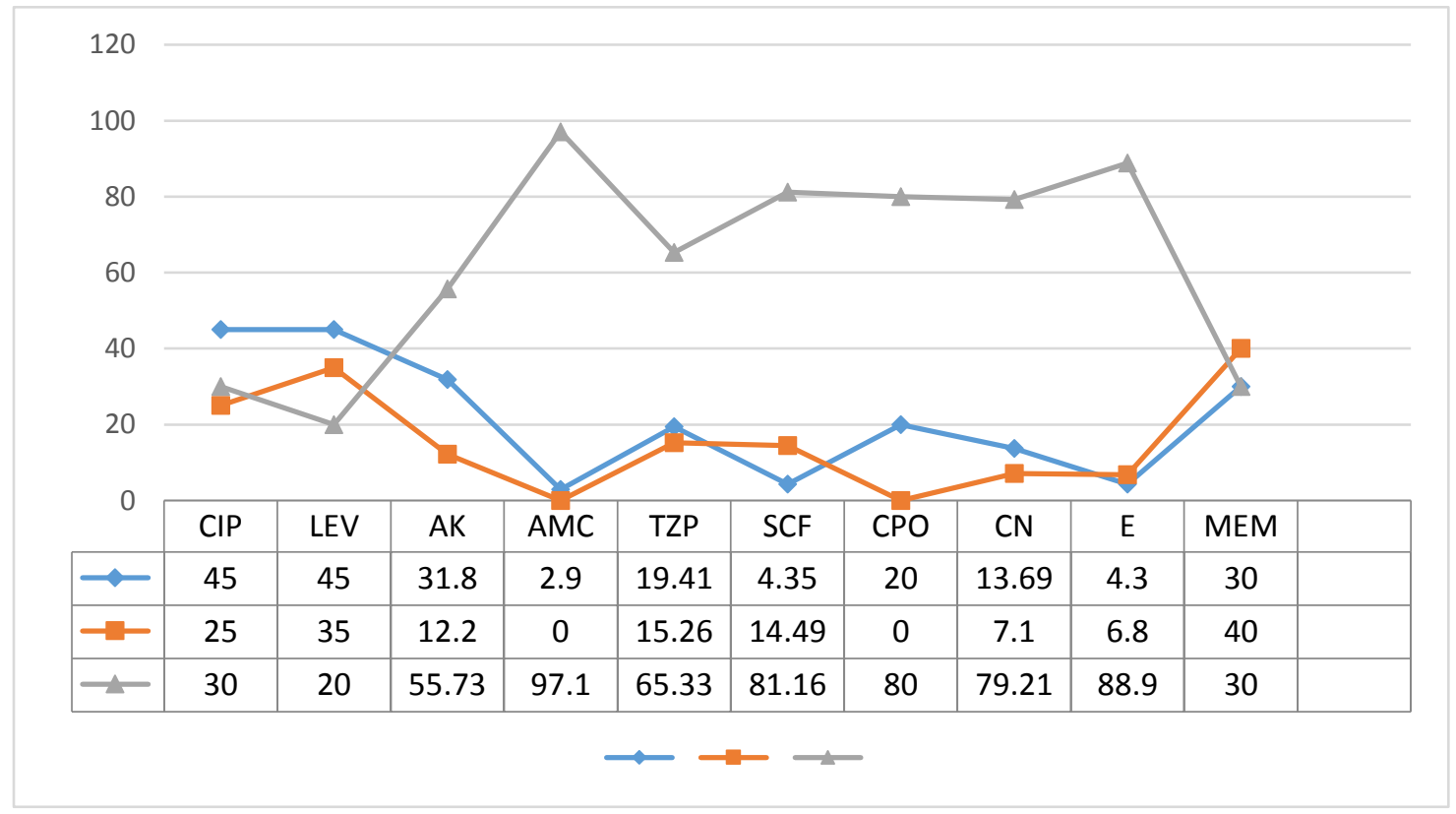

Figure 6. Antibiotic sensitivity against S.aureus 


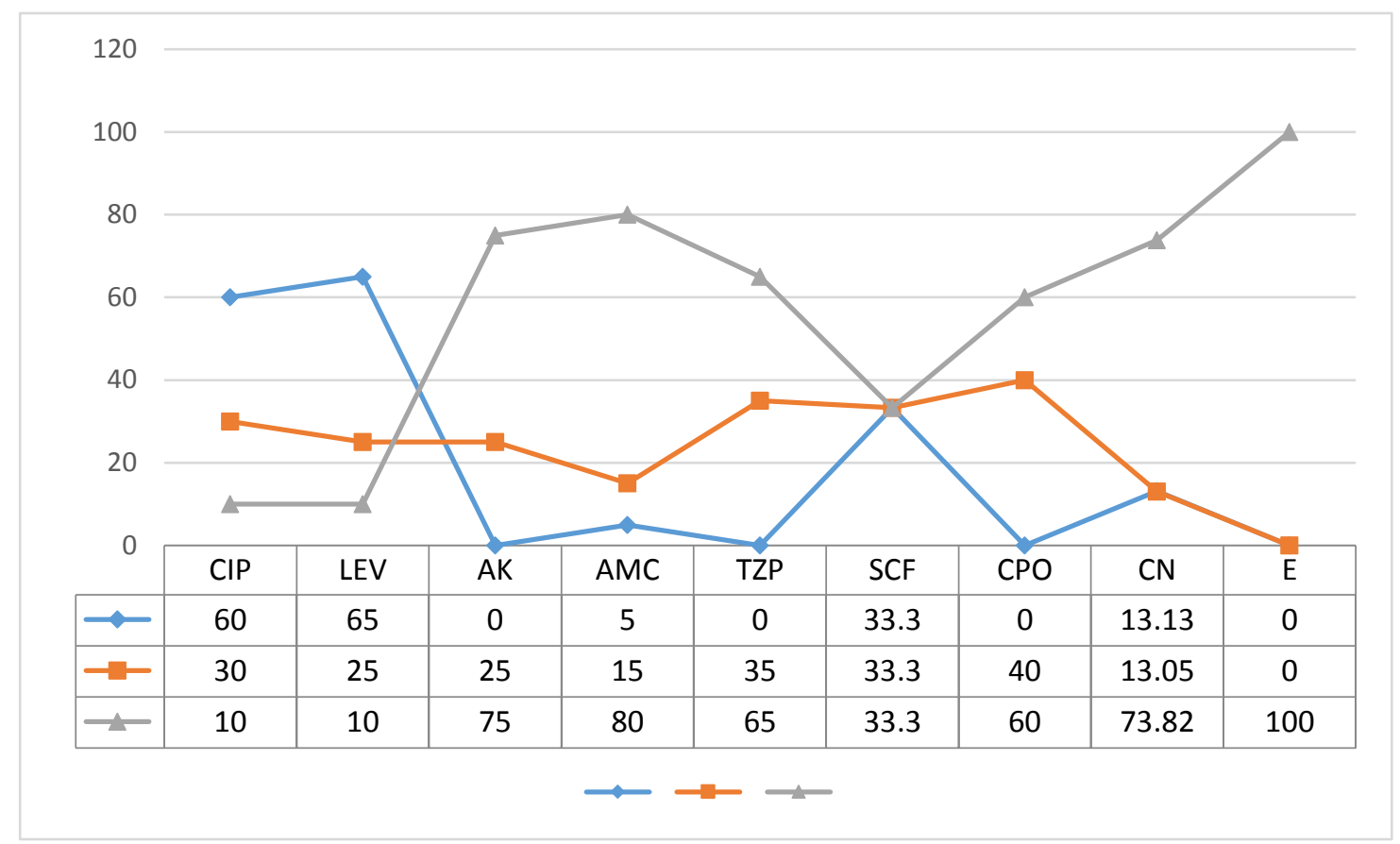

Figure 7. Antibiotic sensitivity against Enterobacter

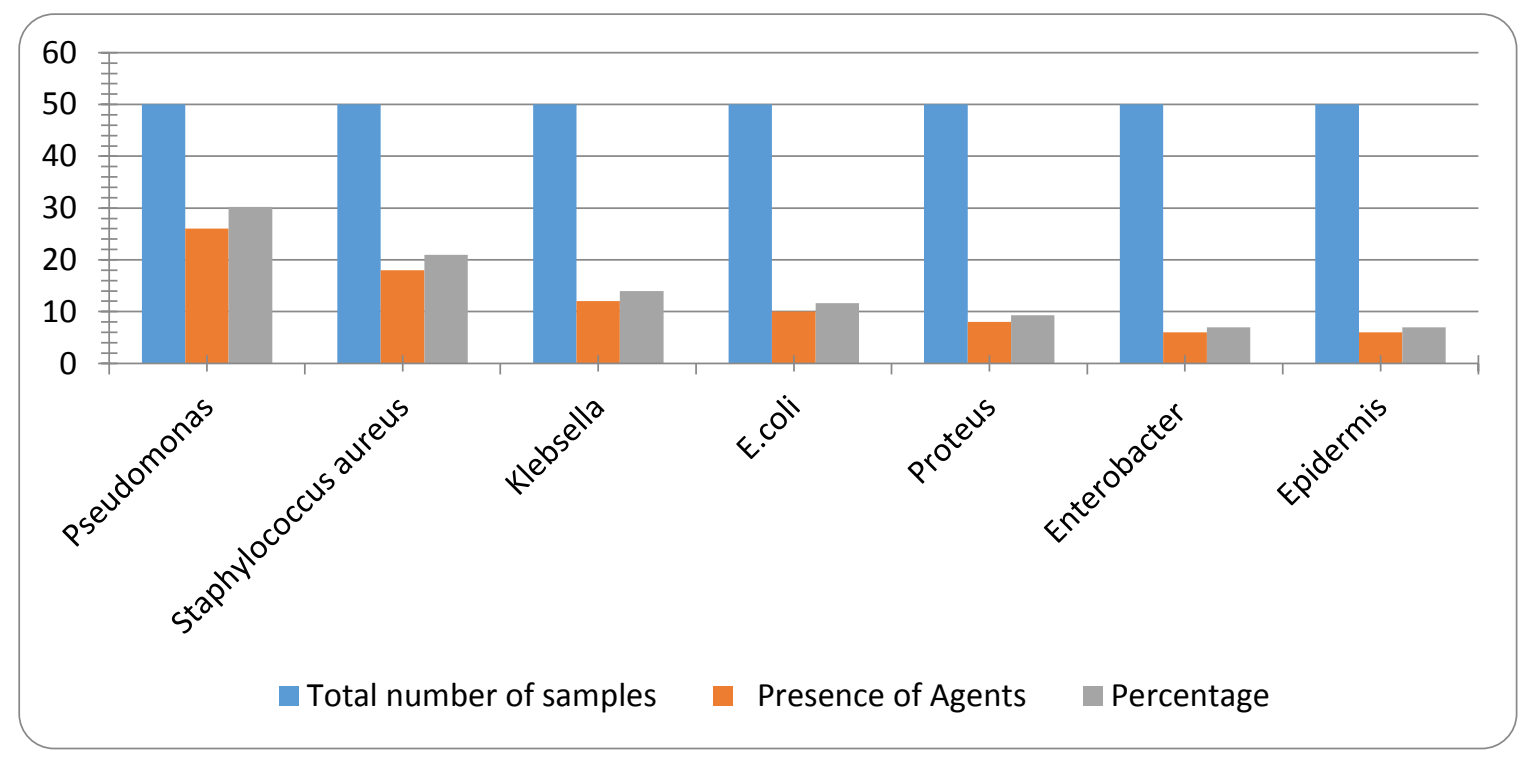

Figure 8. Numbers of Bacteria Isolated From Burn Infection

\section{Conclusion}

Burn is a skin or other body tissues injury caused by various agents including thermal injury, scalds, fire, electrical shock and chemical injury. Various bacteria, e.g. Bacillus, Enterobacter, Epidermis, E. coli, Klebseilla, Pseudomonas Aeruginosa, Proteus and Staphylococcus aureus were isolated lavishly from these injuries. During current research work 12 antibiotics were tested against these bacteria's in which levofloxacin and ciprofloxacin were found more effective than the left over antibiotics.

\section{Authors' contributions}

Conceived and designed the experiments: MN Uddin, Performed the experiments: B 
Jabeen, Q Khan \& S Naeem, Analyzed the data: W Khan \& S Mehmood, Contributed materials/ analysis/ tools: M Rizwan, Wrote the paper: Muhammad

\section{References}

1. Jabir S, Frew Q, El-Muttardi N \& Dziewulski P (2013). "Burn Injuries Resulting from Hot Water Bottle Use: A Retrospective Review of Cases Presenting to a Regional Burns Unit in the United Kingdom," Plastic Surgery International, vol. 2013, Article ID 736368, 7pages, 2013. doi:10.1155/2013/736368.

2. DeBoer S \& O'Connor A (2004). "Prehospital and emergency department burn.

3. Church D, Elsayed S, Reid O, Winston B \& Lindsay R (2006). Burn Wound Infections. Clinical Microbiology Reviews 19 (2): 403-434.

4. Burleson DG, Mason AD \& Pruitt-Jr BA (1988). Lymphoid subpopulation changes after thermal injury and thermal injury with infection in an experimental model. Ann. Surg. 207:208-212.

5. Van-Loey, NE \&Vanson MJ (2003). "Psychopathology and psychological problem in patients with burn scars: epidemiology and management", Am J ClinDermatol4(4):245-72.

6. Gottschlich MM, Mayes T, Khoury JC \& Warden GD (1993) J Am; Diet Assoc. Nov 93(11):1261-8.

7. Barret JP \& Herndon DNP (2003). Last Reconstr Surg. Feb; 111(2):744-50; discussion 751-2.care",Crit Care NursClin North Am16(1):61-73.

8. Wurtz R, Karajovic M, Dacumos E, Jovanovic B \&Hanumadass M (1995). Nosocomial infections in a burn intensive care unit. Burns21: 181-184.

9. Mason, AD, ATMeManus\& BA Pruitt (1986). Association of burn mortaility and bacteremia: a 25 -year review. Arch Surg 121:1027-31.
10. Agnihotri N, Gupta V \& Joshi RM (2004). Aerobic bacterial isolates from burn wound infections and their antibiograms: A five-year study. Burn 30: 241-243.

11. Order SE, Mason AD, Switzer WF \& Moncrief JA (1965). Arterial vascular occlusion and devitalization of burn wounds. Ann Surg 161(4):502-508.

12. Revathi G, Puri J \& Jain BK (1998). "Bacteriology of burns", Burns 24 (4):347-9.

13. Wysocki AB (2002). "Evaluating and managing open skin wounds: colonization infection", AACNClin 13(3):382-9740.

14. Zetola N, Francis JS, Nuermberger EL \&Bishai WR (2005). Communityacquired meticillinresistant Staphylococcus aureus: an emerging threat. Lancet Infect Dis 5: 275-286.

15. Murray CJL \& Lope AD (2006). "The global burden of disease: a comprehensive assessment of mortality and disability from diseases, injuries, and risk factors in 1990 projected to 2020", World Health Organization, Swidzerland.

16. Gales AC, Jones RN, Turnidge J, Rennie R \&Ramphal R.C (2001). LinInfect Dis 32(2):146-155.

17. Japoni A, Hayati M, Alborzi A, Farshad SH \&Abbasian SA (2005). In vitro susceptibility of Pseudomonas aeruginosa isolated from a burn center to silver sulfadiazine and silver nitrate in Shiraz, South of Iran. Iranian J. Med. Sci 30(2): 63-67.

18. Lyczak JB, Cannon CL \& Pier GB (2000). Establishment of Pseudomonas aeruginosa infection: lessons from a versatile opportunist. Microbes and Infection 2: 1051-1060.

19. Hart CA\&Kariuki S (1998). Antimicrobial resistance in developing 
countries. Brit. Med. J 317(7159): 647650.

20. Mooney DP \&Gamelli RL (1989). Sepsis following thermal injury. Comp Ther. 15:22 29.

21. Raja NS \& Singh NN (2007). Antimicrobial susceptibility pattern of clinical isolates of Pseudomonas aeruginosa in tertiary care hospital. $J$ MicrobiolImmunol Infect 40(1): 45- 49.

22. Sheridan RL, Kacmarek RM, McEttrick MM (1995). Permissive Hypercapnia as a Ventilatory Strategy in Burned Children: Effect on Barotrauma, Pneumonia and Mortality. J Trauma 39:854-859.

23. Adeyemi (2006). "Explosions: Obasanjo expresses sadness", The Punch 17(19):7617.

24. Yasemin B, Mehmet $P$, Cenk A \& İrfan $B$ (2013). "Three-year Review of
Bacteriological Profile and Antibiogramof Burn Wound Isolates in Van, Turkey",Int J MedSci10(1):19-23. doi:10.7150/ijms.4723.

25. Embil JM, McLeod JA, Al-Barrak AM, Thompson GM, Aoki FY, Witwicki EJ, Stranc MF, Kabani AM, Nicoll DR \& Nicolle LE (2001). Burns 27(7):681-8.

26. Cheesbrough M (2006). "District Laboratory Practice in Tropical Countries", Part 2 ( $2^{\text {nd }}$ Edition). Cambridge University Press 63-70.

27. Komolafe OO, Ames J, Kalongolera L \& Makoka M (2002). Epidemiology and mortality of burns at the Queen Elizabeth Central Hospital, Blantyre, Malawi. Cent Afr Med J 49: 130-4.

28. Agbenorku P (2013). "Burns functional disabilities among burn survivors: a study in Anokye Teaching Hospital, Ghana", Int J Burns Trauma 3(2):78-86. 